\title{
Transports of acetate and haloacetate in Burkholderia species MBA4 are operated by distinct systems
}

\author{
Xianbin Su, Ka-Fai Kong and Jimmy SH Tsang*
}

\begin{abstract}
Background: Acetate is a commonly used substrate for biosynthesis while monochloroacetate is a structurally similar compound but toxic and inhibits cell metabolism by blocking the citric acid cycle. In Burkholderia species MBA4 haloacetate was utilized as a carbon and energy source for growth. The degradation of haloacid was mediated by the production of an inducible dehalogenase. Recent studies have identified the presence of a concomitantly induced haloacetate-uptake activity in MBA4. This uptake activity has also been found to transport acetate. Since acetate transporters are commonly found in bacteria it is likely that haloacetate was transported by such a system in MBA4.

Results: The haloacetate-uptake activity of MBA4 was found to be induced by monochloroacetate (MCA) and monobromoacetate (MBA). While the acetate-uptake activity was also induced by MCA and MBA, other alkanoates: acetate, propionate and 2-monochloropropionate (2MCPA) were also inducers. Competing solute analysis showed that acetate and propionate interrupted the acetate- and MCA- induced acetate-uptake activities. While MCA, MBA, 2MCPA, and butyrate have no effect on acetate uptake they could significantly quenched the MCA-induced MCAuptake activity. Transmembrane electrochemical potential was shown to be a driving force for both acetate- and MCA- transport systems.
\end{abstract}

Conclusions: Here we showed that acetate- and MCA- uptake in Burkholderia species MBA4 are two transport systems that have different induction patterns and substrate specificities. It is envisaged that the shapes and the three dimensional structures of the solutes determine their recognition or exclusion by the two transport systems.

\section{Background}

Burkholderia species MBA4 is a Gram-negative bacterium enriched from soil using monobromoacetate (MBA) as the sole carbon and energy source for growth. MBA4 can also utilize other haloacids such as monochloroacetate (MCA), 2-monochloropropionate (2MCPA) and 2monobromopropionate (2MBPA) [1]. Since haloacids are environmental pollutants [2-5] and are potentially hazardous for many living organisms [6-8], it is crucial to identify and characterize bacteria that can degrade these alkanoates. The ability for MBA4 to utilize haloacids is conferred by a 2-haloacid dehalogenase Deh4a [1] which has been well characterized [9-11]. A haloacid permease gene, deh $4 p$, which forms an operon with $\operatorname{deh} 4 a$, was

\footnotetext{
* Correspondence: jshtsang@hkucc.hku.hk

Molecular Microbiology Laboratory, School of Biological Sciences, The University of Hong Kong, Pokfulam Road, Hong Kong, Hong Kong
}

identified by means of chromosome walking [12]. The function of Deh4p was confirmed by heterologous expression in E. coli [13], and its topology determined with a PhoA-LacZ dual reporters system [14]. Further characterization of MBA4 showed that a Deh4p paralog, designated as Dehp2, is also playing a role in MCA uptake. The functional role of Dehp2 was confirmed by gene disruption and heterologous expression in E. coli. Single disruptants of deh $4 p$ or $d e h p 2$ were found to have $30 \%$ less of MCA-uptake activity. Moreover, cells with a disrupted deh $4 p$ gene have an enhanced expression in dehp2 and vice versa. It looks like Deh4p has a higher affinity for MCA while Dehp2 prefers chloropropionate. When a deh $4 p^{-} \operatorname{deh} p 2^{-}$double disruptant was constructed, the cells still retain $36 \%$ of MCA-uptake activity. It was concluded that a robust system is present for haloacid uptake in MBA4 [15].

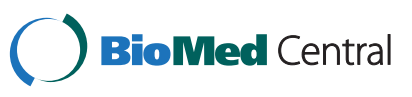

(c) 2012 Su et al.; licensee BioMed Central Ltd. This is an Open Access article distributed under the terms of the Creative Commons Attribution License (http://creativecommons.org/licenses/by/2.0), which permits unrestricted use, distribution, and reproduction in any medium, provided the original work is properly cited. 
In the process of characterizing the MCA-uptake activity of MBA4, it was found that acetate was also recognized by the MCA-inducible uptake system [12,15]. Since acetate and MCA are structurally similar, it is reasonable to speculate that MCA was transported by an acetate-transport system. It has been reported that acetate could freely diffuse across the cell membrane in an un-disassociated form (acetic acid) [16]. However, in growth conditions with a neutral $\mathrm{pH}$ where acetate is mainly in a disassociated form, a specific transport system is needed. There are reports leading to the identification of acetate permeases in many bacterial species, including ActP in Gram-negative E. coli [17] and MctC in Gram-positive Corynebacterium glutamicum [18]. As MBA4 can grow on acetate, it is likely that an acetatetransport system is also present. Whether this acetatetransport system is playing a role in MCA uptake is important to the understanding of the MCA-uptake system in MBA4.

In this study, we analyzed the induction patterns of the acetate- and MCA-uptake systems and determined the substrate specificities of the two systems in cells grown in various substrates. We demonstrated that there are distinct acetate- and MCA- transport system in MBA4. Nonetheless, both systems were sensitive to carbonyl cyanide $m$-chlorophenyl hydrazone indicating that transmembrane electrochemical potential is a driving force for both systems.

\section{Results}

The induction patterns of acetate- and MCA- transport systems are different

Previous analysis showed that MCA-uptake activity of MBA4 was detected only in MCA- and not in acetategrown cells [12]. This indicated that the MCA-uptake activity was induced by MCA and not by acetate. It was also shown that MCA-grown cells possess acetateuptake activity [12]. To check whether a distinct acetatetransport system is present in MBA4, acetate-uptake assays were carried out for pyruvate-, acetate-, and MCA-grown cells. The results showed that pyruvategrown cells had no detectable activity, while both acetate- and MCA-grown cells had significant acetateuptake activities (Figure 1). Acetate-grown cells had an acetate-uptake rate of $111.27 \mathrm{nmol}(\mathrm{mg} \text { protein })^{-1} \mathrm{~min}^{-1}$ for the first $8 \mathrm{~min}$, and MCA-grown cells had a rate of $59.20 \mathrm{nmol}(\mathrm{mg} \text { protein })^{-1} \mathrm{~min}^{-1}$. This indicated that acetate was not entering the cells passively, and there is an inducible acetate-transport system in MBA4.

In order to characterize the inducible acetate-uptake system, MBA4 cells were grown in various carbon sources and their relative acetate-uptake activities, using acetate-grown cells as the standard, determined. Figure $2 \mathrm{~A}$ shows that propionate induced similar level of uptake activity while

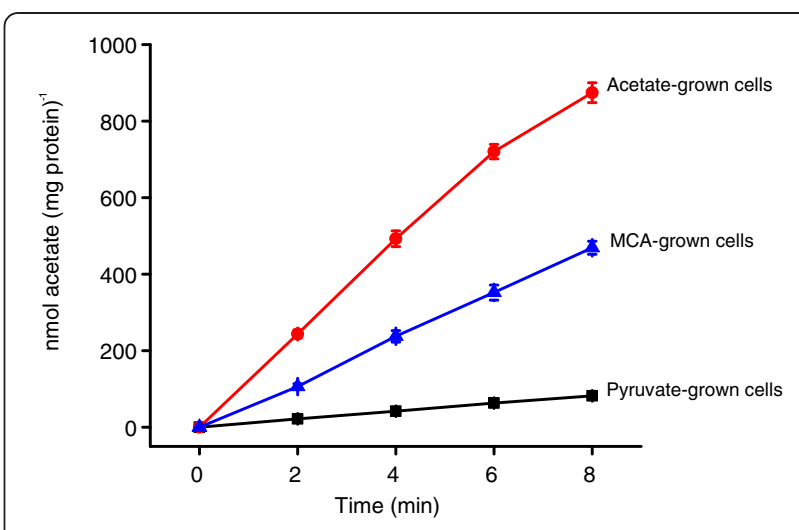

Figure 1 Acetate-uptake activity of MBA4. MBA4 was grown in minimal medium containing pyruvate (squares), acetate (circles), or MCA (triangles). Uptake of $50 \mu \mathrm{M}$ of $\left[2-{ }^{14} \mathrm{C}\right]$ acetate was assayed by a filtration method for a period of $8 \mathrm{~min}$. Data shown are the means of three independent experiments, and the error bars represent the standard deviations.

MCA, MBA and 2MCPA only induced around $50 \%$ of the standard. Butyrate and valerate induced less than $20 \%$ of activity. As a comparison, cells were also grown in similar substrates and their relative MCA-uptake activities determined. Figure $2 \mathrm{~B}$ shows that $\mathrm{MBA}$ induced comparable MCA-uptake activity as MCA but 2MCPA only induced about $20 \%$ of activity. The inductions conferred by acetate, propionate, butyrate, and valerate were rather minimal and only represent a mere $10 \%$ or less. As the MCA-uptake activity was induced significantly only by monohaloacetate while the acetate-uptake activity induced by acetate, haloacetate, propionate and 2MCPA, the induction patterns of the two transport systems appear to be different.

\section{Acetate- and MCA- transport systems have different substrate specificities}

In order to conclude that the transports of acetate and MCA were executed by different systems, competing solute analysis was used to deduce the substrate specificities of the induced acetate- and the MCA- transport systems in MBA4. Acetate uptakes were determined for both acetate- and MCA-grown cells. MCA uptakes were determined only for MCA-grown cells because acetategrown cells have no MCA-uptake activity. Competing solutes that exhibit structural similarity to acetate or propionate were selected.

Acetate uptake of acetate-grown cells was significantly inhibited by acetate and propionate, with an inhibition of $91 \%$ and $90 \%$, respectively (Figure 3A). When MCA-grown cells were used, a similar pattern was observed for acetate uptake. Only acetate and propionate served as effective inhibitors (Figure 3B). When MCA-grown cells were used for MCA-uptake assays, acetate, MCA, MBA, propionate, $2 \mathrm{MCPA}$ and butyrate acted as efficient inhibitors. In addition, glycolate, lactate, and pyruvate also had moderate 


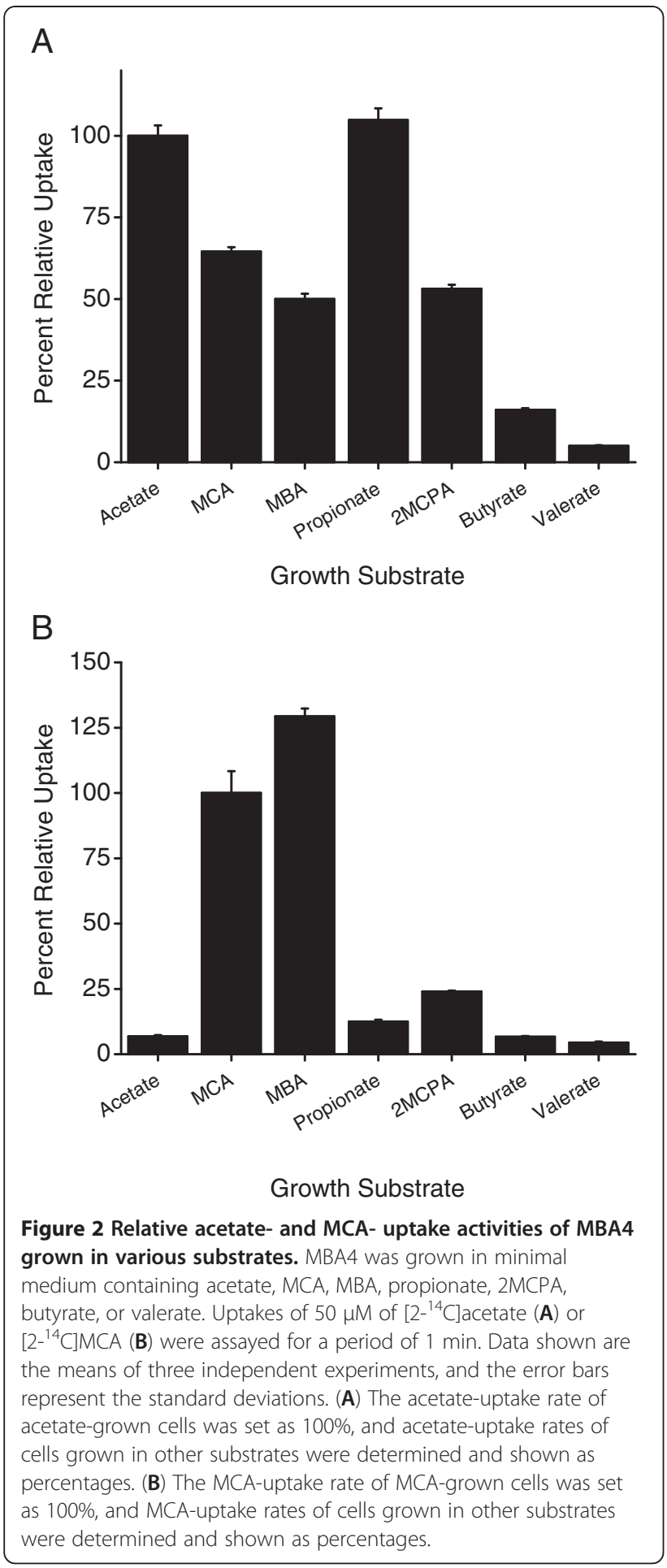

inhibitory effects on MCA uptake as previously reported [12] (Figure 3C). These results showed that the acetateuptake activity was inhibited only by acetate and propionate while the MCA-transport system was inhibited by substrates that display a similar structure as haloacetate.
Transmembrane electrochemical potential is a driving force for both acetate- and MCA- transport

During the characterization of the haloacid operon of MBA4, a protonophore, carbonyl cyanide $m$-chlorophenyl hydrazone (CCCP), was shown to abolish the MCAuptake activity of MBA4 (M. Yu, unpublished). The effect of CCCP on acetate uptake was duly investigated. Figure 4 shows that the inclusion of increasing amount of CCCP in uptake assays for acetate- and MCA-grown cells, the acetate-uptake rates decreased accordingly. The uptake activities were completely abolished when $25 \mu \mathrm{M}$ of CCCP were supplemented in the reactions. As CCCP collapses the proton gradients across the cell membrane [19], acetate uptake in MBA4 is likely to be dependent on the transmembrane electrochemical potentials, a condition similar to that of MCA uptake.

A limitation of employing CCCP is that it cannot discriminate between proton-coupled symport and $\mathrm{Na}^{+}$-coupled symport $[17,20]$. As it is difficult to remove sodium from the buffers completely and radioactive MCA and acetate were provided in the form of a sodium salt, the effect of $\mathrm{pH}$ on acetate- and MCA- uptake was examined with an aim to find out the possible involvement of proton(s). In acetate uptake of acetate-grown cells, the uptake rate decreased steadily as $\mathrm{pH}$ increased from 4 to 8 (Figure 5 , squares). In acetate uptake of MCA-grown cells, the uptake rate increased slightly as $\mathrm{pH}$ increased from 4 to 5 and then dropped gradually as $\mathrm{pH}$ increases (Figure 5 , circles). The uptake rates were much lower than that of acetate-grown cells in similar assay conditions. In MCA uptake of MCAgrown cells, the uptake rate increased slightly as $\mathrm{pH}$ increased from 4 to 6 and dropped swiftly from $\mathrm{pH} 7$ to 8 (Figure 5, triangles). These results showed that acetate- and MCA- transport systems have different sensitivities to $\mathrm{pH}$. Nonetheless, the involvement of proton(s) in acetate transport is noticeable.

\section{Discussion}

In this study, we demonstrated the presence of distinct acetate- and MCA- transport system in MBA4. This is supported by: (i) the observation that the inducible substrates for acetate- and MCA- uptake activity were different; (ii) the two transport systems have different competing solutes and (iii) a difference in dependency on $\mathrm{pH}$ for the two systems. The failure of pyruvategrown cells to take up acetate suggested that the acetate-transport system in MBA4 was inducible. Both acetate and MCA were able to induce acetate-uptake activity although to a different level. Acetate permease MctC of Corynebacterium glutamicum is also inducible. $\mathrm{MctC}$ exhibits a high affinity for acetate and propionate and low affinity for pyruvate. In this case, the expression was higher in pyruvate- than in acetate-grown cells. As a result, both pyruvate- and acetate-grown cells showed 

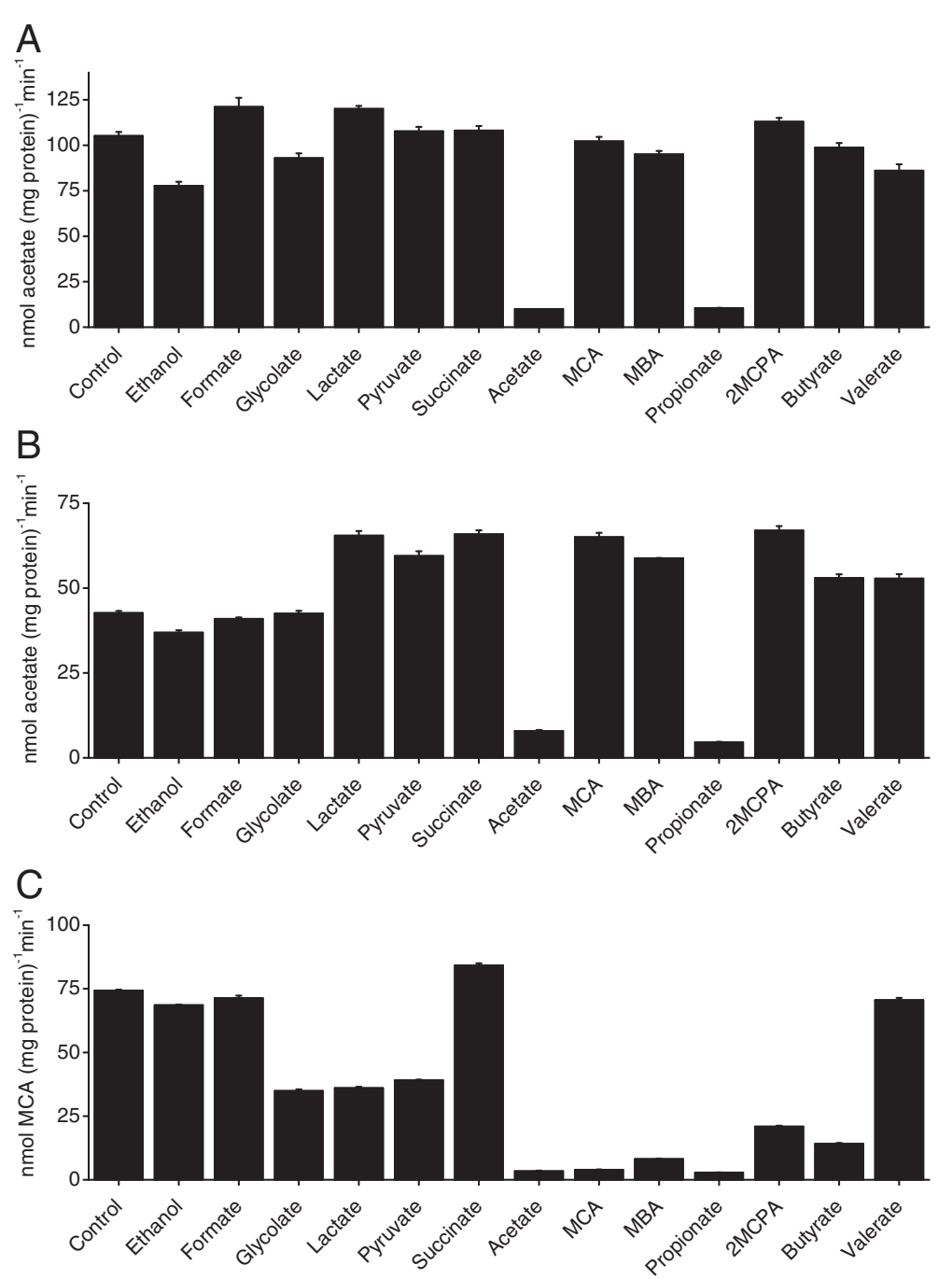

Figure 3 Inhibition of acetate- and MCA- uptake by other solutes. Uptakes of $50 \mu \mathrm{M}$ of $\left[2-{ }^{14} \mathrm{C}\right]$ labelled acetate or MCA were determined in the presence of competing solutes. The assays were conducted for $1 \mathrm{~min}$. Competing solutes were added to a final concentration of $0.5 \mathrm{mM}$. Competing solutes used were: ethanol, formate, glycolate, lactate, pyruvate, succinate, acetate, MCA, MBA, propionate, 2MCPA, butyrate, and valerate. Uptake rates without competitor were used as the controls. Data shown are the means of three independent experiments, and the error bars represent the standard deviations. (A) Acetate uptake of acetate-grown cells; (B) Acetate uptake of MCA-grown cells; (C) MCA uptake of MCA-grown cells.

comparable acetate-uptake activities [18]. In MBA4, no induction was observed for pyruvate while acetate and propionate were the best inducers for acetate uptake. Moreover, they were also the most favourable substrates. It is possible that acetate and propionate were transported by the same transport system but further confirmation is required as Candidatus Competibacter phosphatis appeared to have different transporters for the two solutes [21]. Another acetate permease, ActP of Rhodobacter capsulatus, was produced around 1.5 folds more in acetate- than in pyruvate-grown cells [22]. This indicated that the regulations of various acetatetransport systems in different bacteria are likely to be different and should be compared cautiously.
It is not surprising that MCA-grown cells could take up MCA and acetate because most transporters recognize more than one substrate. Acetate permease ActP of E. coli was able to transport acetate and glycolate [17]. Moreover, acetate and MCA are structurally similar molecules. The ability for MCA-grown cells to transport acetate can be explained by (1) the capability of the induced MCA-transport system to transport acetate; (2) the acetate-transport system was also induced by MCA; and (3) both (1) and (2). Without the identification of the individual permease involved in each of the transport system it is difficult to determine conclusively which the case is. The cloning and heterologous expression of Deh4p in E. coli demonstrated its function as a 


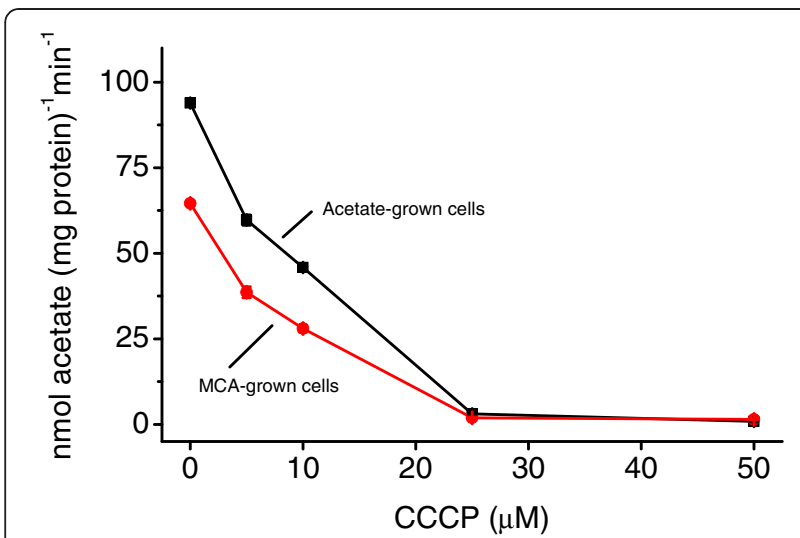

Figure 4 Effect of CCCP on acetate uptake. MBA4 was grown in minimal medium containing acetate (squares) or MCA (circles). Uptakes of $50 \mu \mathrm{M}$ of $\left[2-{ }^{14} \mathrm{C}\right]$ acetate were assayed in the presence of $0,5,10,25$, and $50 \mu \mathrm{M}$ of CCCP for a period of $1 \mathrm{~min}$. Data shown are the means of three independent experiments, and the error bars represent the standard deviations.

dehalogenase-associated MCA-transporter [13]. Similarly, the functional role of Dehp2 as a second MCAtransporter was also demonstrated [15]. Both Deh4p and Dehp2 were capable of recognizing acetate as a substrate. In order to elucidate that the MCA-uptake system, comprising Deh4p and Dehp2, is not the main transporter for acetate, a $\operatorname{deh} 4 p^{-} \operatorname{deh} p 2^{-}$double mutant (strain Ins-4p-p2, [15]) was utilized. Figure 6A shows that the growth of Ins-4p-p2 on acetate was similar to that of wildtype MBA4, if not slightly better. The acetate-uptake rate of this acetate-grown mutant was also assayed and shown to be similar to that of wildtype

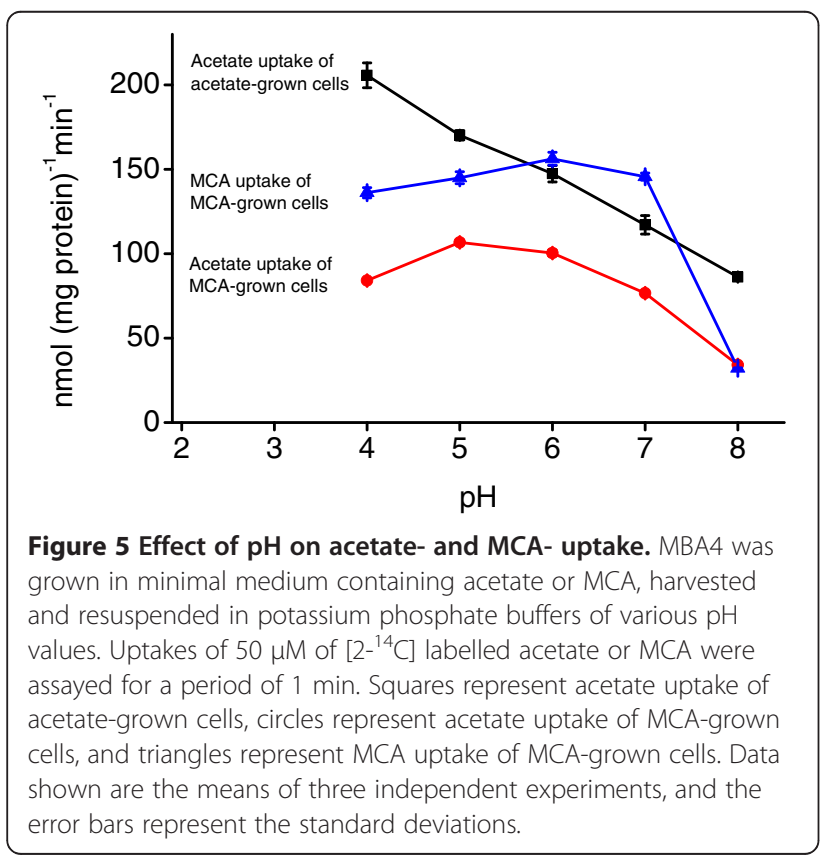

(112.3 nmol (mg protein) $)^{-1} \mathrm{~min}^{-1}$ for mutant and $118.6 \mathrm{nmol}$ (mg protein $)^{-1} \mathrm{~min}^{-1}$ for wildtype, Figure $6 \mathrm{~B}$ ). This suggested that in the absence of the major players in MCA uptake the growth and uptake activity on acetate of the cell were not affected. This confirmed the presence of an independent acetate-transport system other than the MCA-uptake system.

The competing solute analyses show that acetate- and MCA-grown cells have similar inhibition pattern for acetate uptake. This suggested that the acetate-transport system was likely to be induced by MCA. The relatively lower acetate-uptake rate for MCA-grown cells suggested that MCA was a weaker inducer. This is consistent with the observation that acetate and propionate were the best inducers for acetate uptake. The competing solute analyses for MCA-grown cells show that the cells have different inhibition patterns for acetate- and MCA- uptake. The failure of MCA to inhibit the uptake of acetate suggested that the acetate-transport system was expressed and not involved in MCA transport. This is in agreement with the result that acetate-grown cells failed to transport MCA. The ability for acetate to inhibit the MCA-uptake activity of MCA-grown cells concluded that the MCA-uptake activity is different from the acetate-uptake system.

The effect of $\mathrm{pH}$ on the uptakes of acetate of acetateand MCA-grown cells further demonstrates the presence of two systems. The uptake rates of acetate-grown cells decrease linearly with an increase in $\mathrm{pH}$. This shows that proton plays an essential role in the acetate-uptake system. In this condition no MCA-uptake system was produced. When the cells were grown on MCA the rates of acetate uptake on different $\mathrm{pH}$ deviate from that of acetate-grown cells. The competing solute analysis demonstrated a similar pattern of inhibition on acetate uptake for acetate- and MCA-grown cells while the rate was much lower for the latter. It is most likely that the expression of the acetate-uptake system was lower in MCA-grown cells. In this case, the major transport system was that for MCA and which can also transport acetate. Since both acetate- and MCA- transport systems are proton dependent, the $\mathrm{pH}$ dependency of acetate uptake of MCA-grown cells was thus exhibiting a pattern different from that of acetate-grown cells and was displaying a hybrid pattern between acetate uptake of acetate-grown cells and MCA uptake of MCA-grown cells. Future experiments that assay the $\mathrm{pH}$ dependency of acetate uptake of MCA-grown Ins-4p-p2 double mutant could clarify the situation. However, the expressions of other transporters may be affected by the disruptions of deh $4 p$ and dehp2 [15] and could complicate the outcome. Moreover, when the gene responsible for the acetateuptake system has been identified, it is necessary to measure its expression levels in medium containing acetate, 

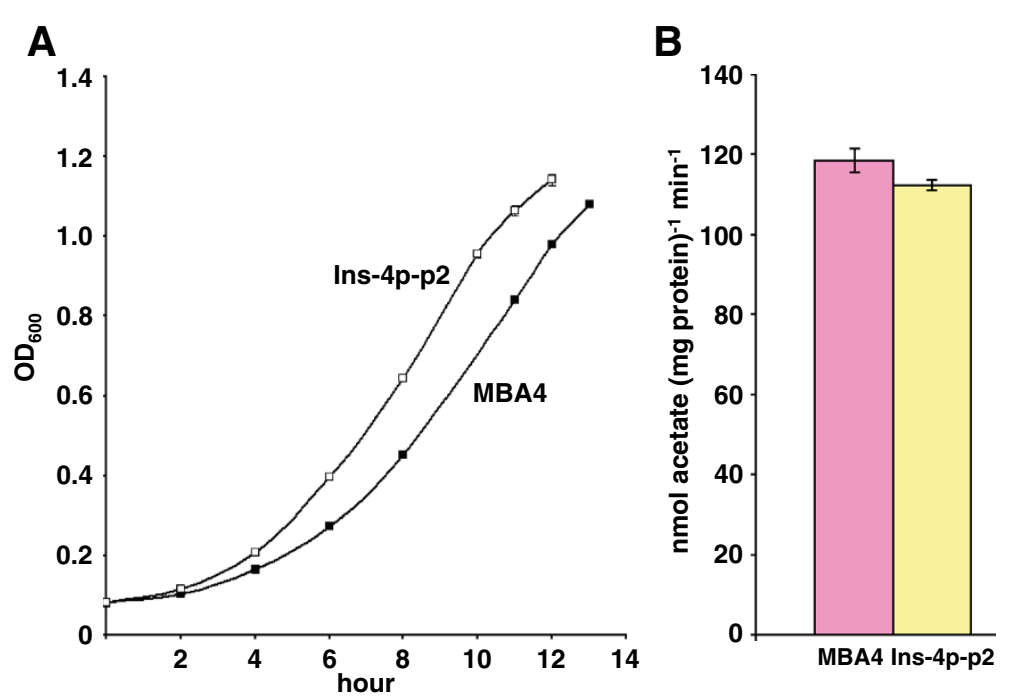

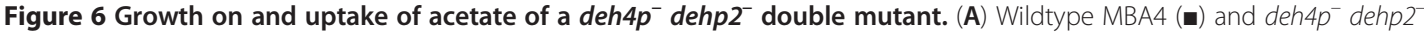
double mutant $(\square)$ were grown in minimal medium containing acetate. Seed cultures were grown in $\mathrm{LB}^{-}$and sub-cultured into minimal medium containing acetate at $30^{\circ} \mathrm{C}$. The optical densities of the cultures were determined at $600 \mathrm{~nm}\left(\mathrm{OD}_{600}\right)$ with a spectrophotometer. (B) Acetate-uptake rates of acetate-grown- wildtype and double mutant. Uptakes of $50 \mu \mathrm{M}$ of $\left[2-{ }^{14} \mathrm{C}\right]$ acetate were assayed by a filtration method for a period of $2 \mathrm{~min}$. Data shown are the means of three independent experiments, and the error bars represent the standard deviations.

MCA and other substrates in order to characterize the system fully.

The most distinct difference between the two transport systems is their substrate specificity. The failure of ethanol to inhibit acetate transport suggested that the carboxyl group is likely to be an important element. The lack of inhibition by formate implied that the presence of a second carbon is also essential. The failure of MCA,
MBA, and 2MCPA to inhibit acetate transport indicated that the substituted halogen atom affected the effective recognition. The acetate-uptake ability of MBA4 was inhibited by propionate but not by butyrate. This is consistent with the acetate permease ActP of E. coli [17]. The failure of butyrate and valerate to act as a competing solute suggested that a molecule with more than three carbons would be less effective for the acetate-

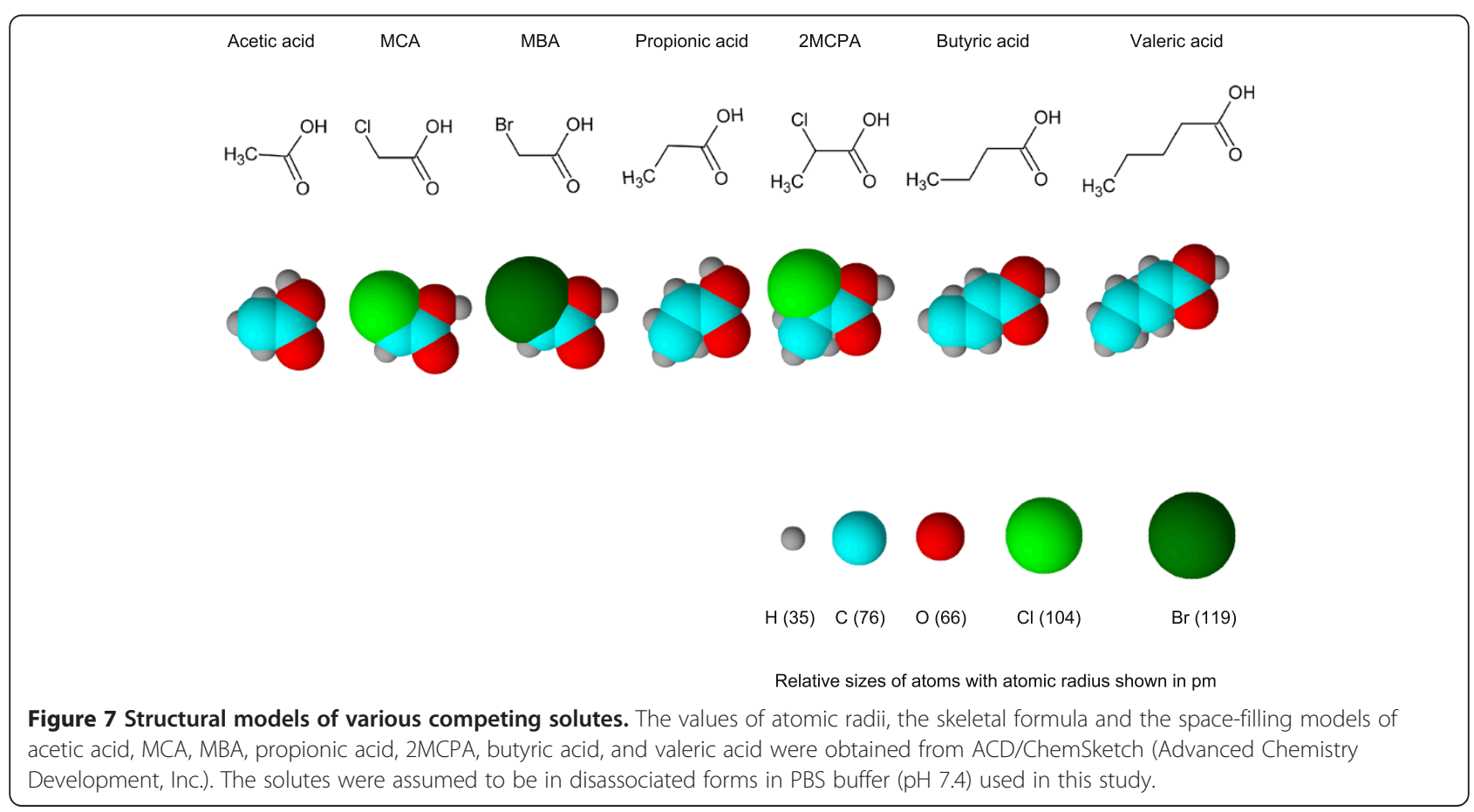


uptake system. In summary, MCA, MBA, 2MCPA, and butyrate could inhibit MCA- but not acetate- uptake of MBA4. A visual inspection of the structural models of these molecules (Figure 7) suggests that they are generally larger than acetate. Similarly, MCA, MBA, and propionate have a stronger inhibitory effect on MCA uptake than 2MCPA and butyrate. The failure of valerate to act as a competing solute further strengthens the notion that size is a determining factor. By means of comparing the structures of the competing solutes it may be possible to estimate the range of substrates recognized by various transport systems and provide valuable information on the functional property of the transporters.

The inducers for the acetate-uptake system are acetate, MCA, MBA, propionate, and 2MCPA, but only acetate and propionate are substrates. Similarly, the inducers for the MCA uptake system are MCA, MBA and to a lesser extend 2MCPA, while the substrates include the inducers, acetate and propionate. The inducer and the substrate are not necessarily the same. Although the acetate- and the MCA- transport systems have different induction patterns and substrate specificities, they do share certain similarity. The activities of both systems were abolished by CCCP, suggesting transmembrane electrochemical potential as a driving force. As CCCP could not discriminate between proton- and sodiumcoupled symport, it was unclear which was/were involved in the transports. Previous studies of bacterial acetate-transport systems failed to give a uniformed conclusion. Although ActP of $E$. coli was assigned to the sodium:solute symporter family, no dependency on sodium was demonstrated [17]. While electrochemical proton potential was confirmed to be a driving force for MctC of Corynebacterium glutamicum [18], acetate uptake in Accumulibacter spp. was believed to be driven by proton motive force, and in Defluviicoccus spp. it was suggested to be powered by proton or sodium gradient or both [23]. An increased uptake of acetate for a change of $\mathrm{pH}$ from 8 to 4 affirmed the involvement of proton in acetate transport in MBA4. However, the involvement of sodium could not be ruled out and further confirmation is required.

\section{Conclusions}

The uptakes of acetate and MCA in Burkholderia species MBA4 were demonstrated to be manoeuvred by different transport systems. These systems have different induction patterns and substrate specificities. A driving force for both systems is transmembrane electrochemical potential, and proton is involved in acetate transport. A structural comparison of the competing solutes suggests that the size of the molecule is a determinant factor for recognition. Future work on identification and characterization of the transporter protein is required to understand the systems comprehensively.

\section{Methods}

\section{Bacterial strains and culture conditions}

Burkholderia species MBA4 and mutant Ins-4p-p2 were grown at $30^{\circ} \mathrm{C}$ in Luria Bertani medium without $\mathrm{NaCl}$ ( $\mathrm{LB}^{-}, 1 \%$ tryptone, $0.5 \%$ yeast extract) or in defined minimal medium [1] with $0.5 \mathrm{~g}$ carbon liter $^{-1}$ of pyruvate, acetate, MCA, MBA, propionate, 2MCPA, butyrate, or valerate.

\section{Transport assays}

MBA4 was cultured in minimal medium with pyruvate, acetate, MCA, MBA, propionate, 2MCPA, butyrate, or valerate to late logarithmic phase, with an optical density value $\left(\mathrm{OD}_{600}\right)$ of $1.0-1.2,0.9-1.1,0.5-0.7,0.7-0.9,0.9-1.1$, $0.1-0.2,0.9-1.1$ or $0.9-1.1$, respectively. Cells were harvested by centrifugation, washed twice with phosphate buffered saline (PBS, Fluka), and adjusted to an $\mathrm{OD}_{600}$ of around 0.4. For standard transport assays, $30 \mu \mathrm{l}$ of $\left[2-{ }^{14} \mathrm{C}\right] \mathrm{MCA}$ (Sigma-Aldrich, diluted to $0.25 \mathrm{mM}$ in PBS) or $\left[2-{ }^{14} \mathrm{C}\right.$ ]acetate (Sigma-Aldrich, diluted to $0.25 \mathrm{mM}$ in PBS) were added to $120 \mu \mathrm{l}$ of prepared cells, mixed, and $30 \mu \mathrm{l}$ samples were taken at various time points. Filtration and washing of cells, determinations of total protein and trapped $\left[2-{ }^{14} \mathrm{C}\right] \mathrm{MCA}$ or $\left[2-{ }^{14} \mathrm{C}\right]$ acetate were carried out as previously described [12].

To determine the substrate specificity, diluted $\left[2-{ }^{14} \mathrm{C}\right]$ MCA or $\left[2-{ }^{14} \mathrm{C}\right]$ acetate was mixed with $10 \times$ competing solutes in PBS before adding to the prepared cells. Percent relative uptake was calculated as (Uptake rate with competing solute/Uptake rate without competing solute) $\times 100 \%$. The competing solutes included: ethanol; onecarbon monocarboxylate formate; two-carbon glycolate, acetate, MCA and MBA; three-carbon propionate, lactate, pyruvate and 2MCPA; four-carbon butyrate, fivecarbon valerate; and four-carbon dicarboxylate succinate. The skeletal formulas and space-filling models of acetic acid, MCA, MBA, propionic acid, 2MCPA, butyric acid, and valeric acid were drawn with $\mathrm{ACD} / \mathrm{ChemSketch}$ (Advanced Chemistry Development, Inc.).

To study the effect of protonophore on uptake assay, appropriate amounts of carbonyl cyanide $m$-chlorophenyl hydrazone (CCCP) were mixed with prepared cells to a final concentration of $0,5,10,25$, and $50 \mu \mathrm{M}$ for $30 \mathrm{~min}$ before transport assays were conducted.

To determine the effect of $\mathrm{pH}$ on transport systems, $100 \mathrm{mM}$ potassium phosphate buffers of different $\mathrm{pH}$ values (4 to 8 ) were used to resuspend the bacterial cells and for diluting $\left[2-{ }^{14} \mathrm{C}\right] \mathrm{MCA}$ and $\left[2-{ }^{14} \mathrm{C}\right]$ acetate for uptake assays.

\section{Abbreviations}

MCA: Monochloroacetate; MBA: Monobromoacetate; 2MCPA: 2-

Monochloropropionate; 2MBPA: 2-Monobromopropionate; CCCP: Carbonyl

Cyanide M-Chlorophenyl Hydrazone; PBS: Phosphate Buffered Saline.

\section{Competing interests}

The authors declare that they have no competing interests. 


\section{Authors contributions}

XS and KFK designed and carried out the studies and drafted the manuscript. JSHT conceived of the study, participated in the design and coordination of the study and drafted the manuscript. All authors read and approved the final manuscript.

\section{Acknowledgements}

We thank WK Yip for the use of a scintillation counter. XS thanks the University of Hong Kong for a studentship. This work was partially supported by the University Seed Funding Programme for Basic Research 2011.

Received: 4 June 2012 Accepted: 17 November 2012

Published: 20 November 2012

\section{References}

1. Tsang JSH, Sallis PJ, Bull AT, Hardman DJ: A monobromoacetate dehalogenase from Pseudomonas cepacia MBA4. Arch Microbiol 1988, 150(5):441-446.

2. Martin JW, Mabury SA, Wong CS, Noventa F, Solomon KR, Alaee M, Muir DC: Airborne haloacetic acids. Environ Sci Technol 2003, 37(13):2889-2897.

3. Peters RJB: Chloroacetic acids in European soils and vegetation. $J$ Environ Monit 2003, 5(2):275-280.

4. Chang HH, Tung HH, Chao CC, Wang GS: Occurrence of haloacetic acids (HAAs) and trihalomethanes (THMs) in drinking water of Taiwan. Environ Monit Assess 2010, 162(1-4):237-250.

5. Cardador MJ, Gallego M: Haloacetic acids in swimming pools: swimmer and worker exposure. Environ Sci Technol 2011, 45(13):5783-5790.

6. Bull RJ: Mode of action of liver tumor induction by trichloroethylene and its metabolites, trichloroacetate and dichloroacetate. Environ Health Perspect 2000, 108 Supplement 2:241-259.

7. Dote T, Kono K, Usuda K, Shimizu H, Tanimoto Y, Dote E, Hayashi S: Systemic effects and skin injury after experimental dermal exposure to monochloroacetic acid. Toxicol Ind Health 2003, 19(7-10):165-169.

8. Plewa MJ, Simmons JE, Richardson SD, Wagner ED: Mammalian cell cytotoxicity and genotoxicity of the haloacetic acids, a major class of drinking water disinfection by-products. Environ Mol Mutagen 2010, 51(8-9):871-878.

9. Tsang JSH, Pang BCM: Identification of the dimerization domain of dehalogenase IVa of Burkholderia cepacia MBA4. Appl Environ Microbiol 2000, 66(8):3180-3186.

10. Pang BCM, Tsang JSH: Mutagenic analysis of the conserved residues in dehalogenase IVa of Burkholderia cepacia MBA4. FEMS Microbiol Lett 2001, 204(1):135-140.

11. Schmidberger JW, Wilce JA, Tsang JSH, Wilce MC: Crystal structures of the substrate free-enzyme, and reaction intermediate of the HAD superfamily member, haloacid dehalogenase DehIVa from Burkholderia cepacia MBA4. J Mol Biol 2007, 368(3):706-717.

12. Yu M, Faan YW, Chung WYK, Tsang JSH: Isolation and characterization of a novel haloacid permease from Burkholderia cepacia MBA4. Appl Environ Microbiol 2007, 73(15):4874-4880.

13. Yu M, Tsang JSH: Use of ribosomal promoters from Burkholderia cenocepacia and Burkholderia cepacia for improved expression of transporter protein in Escherichia coli. Protein Expr Purif 2006, 49(2):219-227.

14. Tse YM, Yu M, Tsang JSH: Topological analysis of a haloacid permease of a Burkholderia sp. bacterium with a PhoA-LacZ reporter. BMC Microbiol 2009, 9:233.

15. Su X, Tsang JSH: Existence of a robust haloacid transport system in a Burkholderia species bacterium. Biochim Biophys Acta 2012, http://dx.doi. org/10.1016/j.bbamem.2012.09.017.

16. Wolfe AJ: The acetate switch. Microbiol Mol Biol Rev 2005, 69(1):12-50

17. Gimenez R, Nunez MF, Badia J, Aguilar J, Baldoma L: The gene yjcG, cotranscribed with the gene acs, encodes an acetate permease in Escherichia coli. J Bacteriol 2003, 185(21):6448-6455.

18. Jolkver E, Emer D, Ballan S, Krämer R, Eikmanns BJ, Marin K: Identification and characterization of a bacterial transport system for the uptake of pyruvate, propionate, and acetate in Corynebacterium glutamicum. J Bacterio/ 2009, 191(3):940-948.

19. Kasianowicz J, Benz R, McLaughlin S: The kinetic mechanism by which CCCP (carbonyl cyanide $\mathrm{m}$-chlorophenylhydrazone) transports protons across membranes. J Membr Biol 1984, 82(2):179-190.
20. Hosie AHF, Allaway D, Poole PS: A monocarboxylate permease of Rhizobium leguminosarum is the first member of a new subfamily of transporters. J Bacteriol 2002, 184(19):5436-5448.

21. Oehmen A, Yuan Z, Blackall LL, Keller J: Comparison of acetate and propionate uptake by polyphosphate accumulating organisms and glycogen accumulating organisms. Biotechnol Bioeng 2005, 91(2):162-168.

22. Borghese R, Cicerano S, Zannoni D: Fructose increases the resistance of Rhodobacter capsulatus to the toxic oxyanion tellurite through repression of acetate permease (ActP). Antonie Van Leeuwenhoek 2011, 100(4):655-658.

23. Burow LC, Mabbett AN, McEwan AG, Bond PL, Blackall LL: Bioenergetic models for acetate and phosphate transport in bacteria important in enhanced biological phosphorus removal. Environ Microbiol 2008, 10(1):87-98.

doi:10.1186/1471-2180-12-267

Cite this article as: Su et al:: Transports of acetate and haloacetate in Burkholderia species MBA4 are operated by distinct systems. BMC Microbiology 2012 12:267.

\section{Submit your next manuscript to BioMed Central and take full advantage of:}

- Convenient online submission

- Thorough peer review

- No space constraints or color figure charges

- Immediate publication on acceptance

- Inclusion in PubMed, CAS, Scopus and Google Scholar

- Research which is freely available for redistribution

Submit your manuscript at www.biomedcentral.com/submit
C Biomed Central 